
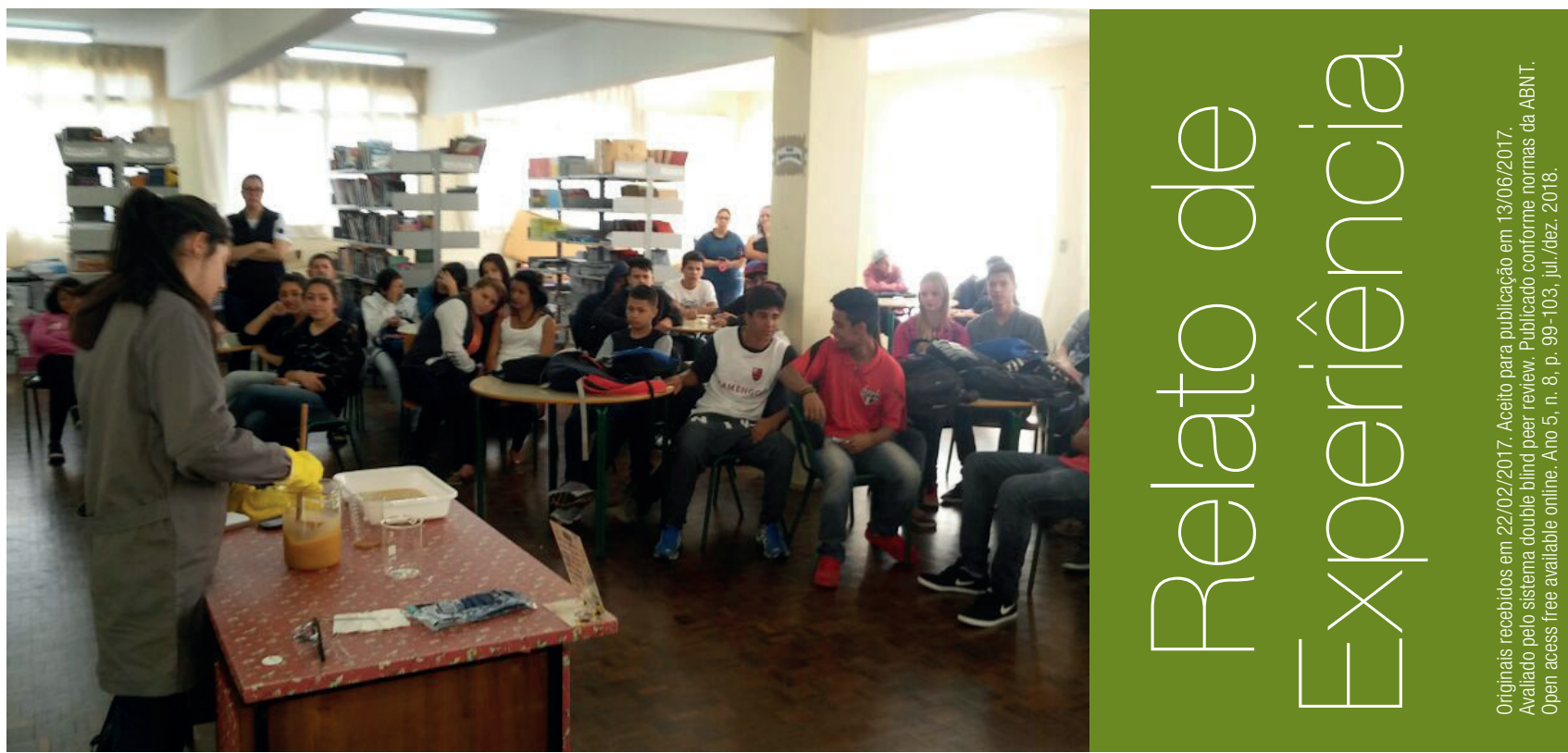

\title{
Produção de sabão: reutilização do óleo de soja em oficinas de Química
}

\author{
Ricardo Guz1 - ricardo.guz@ifsc.edu.br \\ João Henrique Alves Grava Molina²- joao.molina@ifsc.edu.br \\ Izabela Cardoso ${ }^{3}$ - izabelacardoso19@gmail.com
}

\section{RESUMO}

Visando reduzir o descarte de forma incorreta na natureza, do óleo de cozinha, e reduzir o impacto ambiental para evitar a degradação ecológica, realizaram-se oficinas no IFSC - Caçador, e em outra instituição de ensino da cidade, aplicando conceitos químicos na obtenção do óleo de soja e sua reação quando em contato com alguma substância saponificante $(\mathrm{NaOH})$. Desta maneira, aplicou-se de forma prática o conteúdo de química orgânica, de modo a tentar desobstruir a lacuna existente no conteúdo teórico e facilitar, assim, 0 entendimento pelos alunos.

\section{PALAVRAS-CHAVE}

Ensino de Química. Química Experimental. Óleo de cozinha. Sabão.

\section{ABSTRACT}

In order to reduce the incorrect disposal of cooking oil in nature, and reduce the environmental impact to avoid ecological degradation. Workshops were held at the IFSC - Caçador, and at another educational institution in the city, applying chemical concepts in obtaining soybean oil, and its reaction when in contact with some saponifying substance $(\mathrm{NaOH})$. In this way the

\footnotetext{
1 Graduado em Química Industrial e Licenciatura em Química pela UTFPR - Câmpus Pato Branco, Mestre em Tecnologia de Processos Químicos e Bioquímicos pela mesma instituiçã̃o. Professor no IFSC - Câmpus Caçador.

2 Graduado em Química e Licenciatura em Ciências com Habilitação em Química pela USC - Câmpus Bauru, Especialização em Docência no Ensino Superior pela UNOPAR. Mestrando no Programa em Desenvolvimento e Sociedade da UNIARP. Professor no IFSC - Câmpus Caçador.
}

3 Graduanda do curso superior em Engenharia de Produção no IFSC - Câmpus Caçador. 
content of organic chemistry was applied in a practical way, in order to try to unclog the gap in the theoretical content, and thus facilitate the students understanding.

\section{KEYWORDS}

Chemistry teaching. Experimental Chemistry. Kitchen oil. Soap.

\section{Relato de experiência}

Sabe-se que a educação é uma das ferramentas de incentivo para a mobilidade e o bemestar social, bem como outros aspectos como saúde, paz, justiça e conservação de meio ambiente que estão relacionados à educação (PINTO-COELHO; HAVENS, 2016).

Os óleos são substâncias que possuem grande aplicação nas indústrias alimentícias, farmacêuticas, de sabões, entre outras. São formados por triésteres, pois possuem três grupos ésteres em sua estrutura e se caracterizam por sua natureza hidrofóbica e solubilidade em ácidos graxos (TOLENTINO, 2015). Assim, quando o óleo de cozinha não possui uma destinação correta e acaba sendo descartado no esgoto comum, o mesmo pode gerar inúmeros impactos ao meio ambiente que influenciam diretamente na sociedade, como, por exemplo, através do entupimento de tubulações. Isto porque, quando o óleo chega aos rios, o mesmo forma uma película em sua superfície, o que acaba impedindo a passagem de luz e oxigênio, evitando o desenvolvimento e provocando a morte de espécies aquáticas, como as algas que necessitam dessa radiação e oxigenação para sua sobrevivência (ALBERICl; PONTES, 2004). Em relação aos impactos ocasionados pelo descarte inadequado do óleo, estima-se que um litro de óleo de cozinha usado pode vir a poluir cerca de um milhão de litros de água (LUCENA; ALBUQUERQUE; MOURA, 2014).

Neste contexto, para a execução das oficinas didáticas, realizou-se um prévio estudo sobre a importância da proteção ao meio ambiente e de como a educação pode fornecer formas para ampliar este conhecimento e conscientizar os alunos, visando à promoção de uma sociedade mais emancipada e engajada na luta contra a contaminação dos recursos naturais. Assim, com o objetivo de reaproveitar o óleo de cozinha e demonstrar o ensino ambiental, abordaram-se os seguintes contextos químicos presente no processo de fabricação do sabão caseiro:

- A composição do óleo: Que possui os ácidos graxos superiores (C12 - C22) e glicerol como estrutura formadora. Os triacilgliceróis que se encontram em estado líquido, em temperatura ambiente, são chamados de óleos, e quando estão no estado sólido chamamse gorduras (ALLINGER et al., 2009).

- Reação de esterificação: 0 processo de formação do sabão é decorrente da reação de saponificação, a qual consiste na reação de um éster com uma base de forma a produzir um álcool e o sal de um ácido (ALLINGER et al., 2009).

- Agentes tensoativos e miscibilidade das substâncias: Sabões e detergentes possuem em sua estrutura molecular uma parte hidrofílica, a qual possui afinidade com a água, e uma parte hidrofóbica, a qual possui aversão à água. A capacidade de limpeza de um sabão é definida pela capacidade que o mesmo tem de formar emulsões (ALLINGER et al., 2009). A formação da micela justifica a solubilidade dos sabões em água, uma vez que as cadeias apolares do sabão permanecem em ambiente apolar e os grupos polares em contato com um ambiente polar (SOLOMONS; FRYHLE, 2011).

Aplicaram-se ao todo quatro oficinas, sendo duas no próprio IFSC-Caçador, durante a Semana Nacional de Ciência e Tecnologia (SNCT) de 2016, representado pela Figura 1 , onde receberam alunos da rede estadual de ensino, e outras duas oficinas em outra instituição de ensino da cidade. Com estas oficinas buscava-se, assim, impactar diretamente as famílias e a comunidade que receberam estas informações, possibilitando implantar o pensamento sustentável dentro da localidade de cada aluno. 


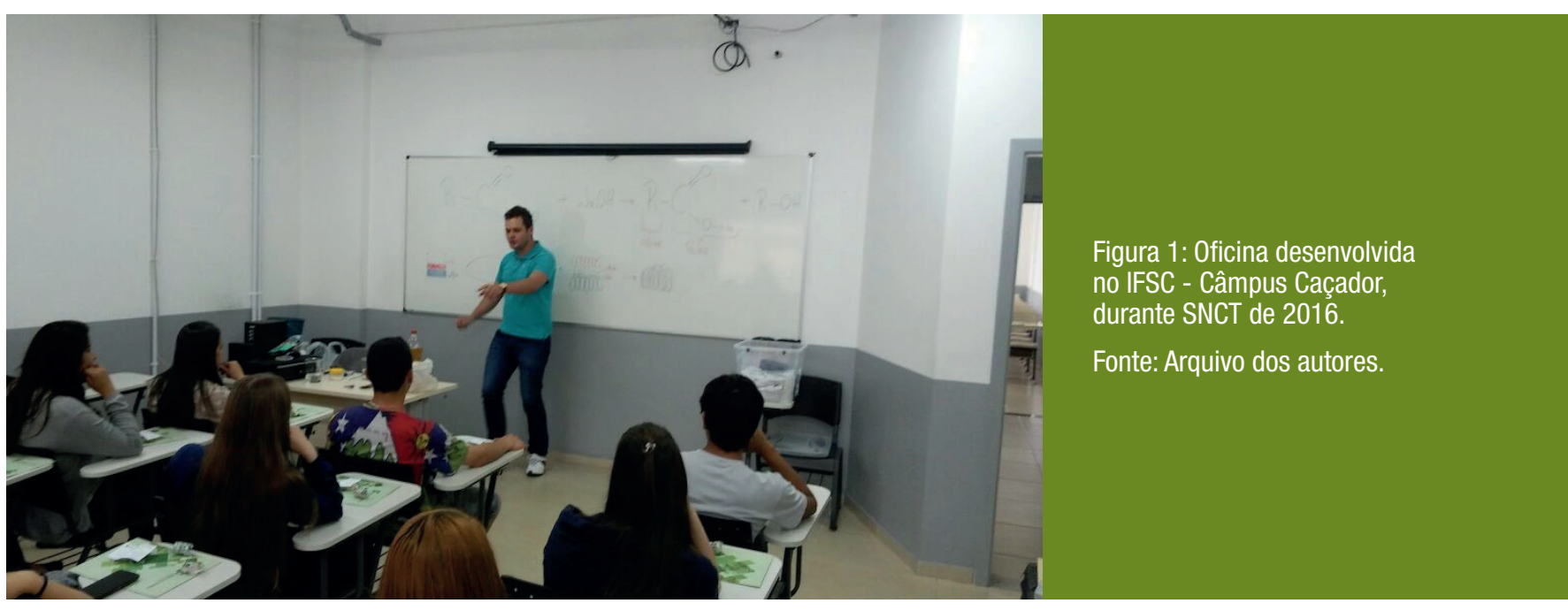

Iniciaram-se as atividades com conscientização das ações humanas individuais, que podem impactar o coletivo da sociedade e do meio ambiente. Debateu-se sobre a importância da higiene e como os produtos químicos de limpeza facilitam a execução deste trabalho e destacou-se ainda que quando não damos a devida atenção ao descarte de materiais o resultado transcreve-se na forma de degradação dos recursos naturais. Após as reflexões e debates, iniciou-se a preparação do sabão caseiro a partir do óleo de fritura usado. Destacamos dois pontos sobre o projeto: primeiro, que o mesmo contou com a participação de uma aluna bolsista do curso superior em Engenharia de Produção, ofertado pelo IFSC - Caçador e, segundo, que esta aluna desenvolveu e ministrou as oficinas com os alunos, nas instituições visitadas pelo projeto, conforme Figura 2, sob a supervisão de seus professores-orientadores, demonstrando inicialmente todo o processo e auxiliando os alunos na sua execução.

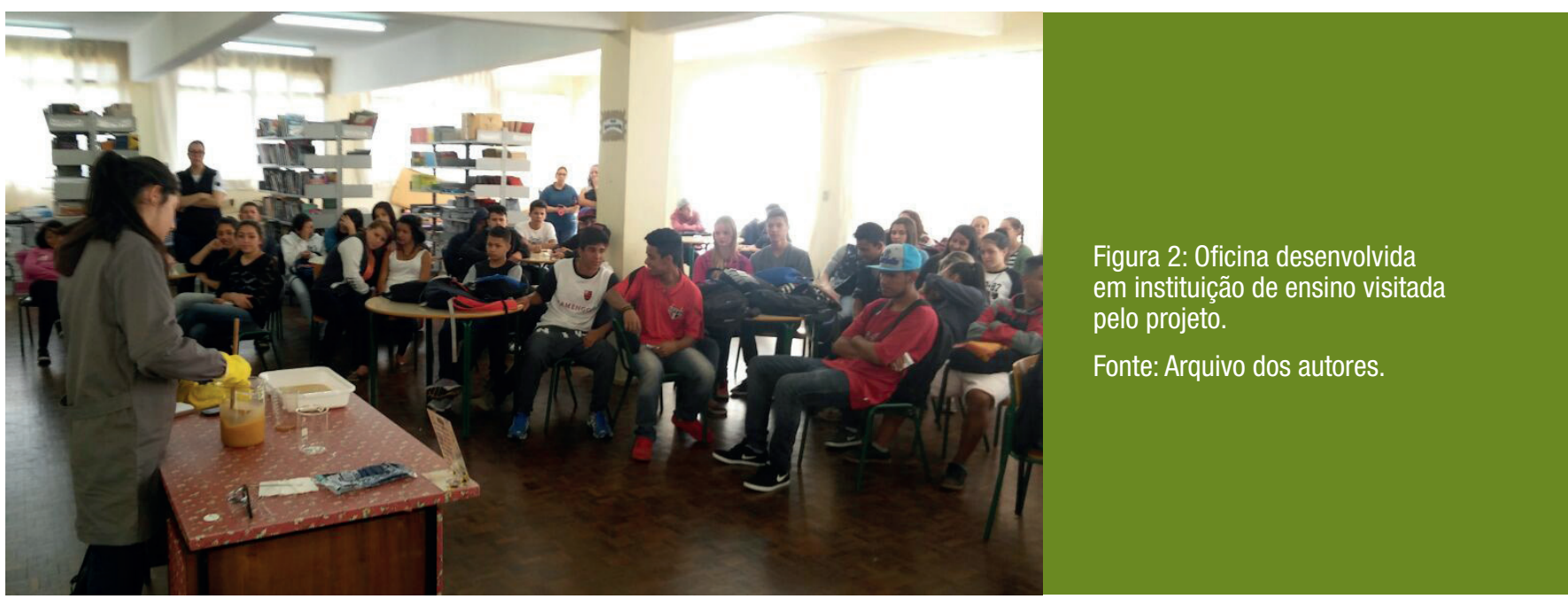

Os alunos receberam um material impresso contendo as informações de como seria preparado o sabão caseiro, conforme Figura 3. Iniciou-se o processo, pesando 80,00 gramas de soda cáustica comercial, aferiu-se 300,00 mL de água e 500,00 mL de óleo já utilizado em frituras. Então, dissolveu-se a soda cáustica na água e adicionou-se lentamente o óleo, de maneira a iniciar o processo de saponificação e originar o sabão. Agitou-se constantemente por 20 minutos; transferiu-se para outro recipiente e aguardou solidificar. Durante este tempo, repassou-se os conceitos químicos envolvidos, de reação de esterificação e agentes tensoativos. Orientou-se os alunos a tomarem basicamente dois cuidados ao realizar estes procedimentos: i) não reproduzirem sem os cuidados de um adulto; ii) ao dissolver a soda cáustica, sempre adicionar a soda na água e nunca 0 contrário (água na soda). 
Figura 3 - Metodologia para produção do sabão caseiro.

Fonte: Elaborado pelos autores.

INSTITUTO FEDERAL

Santa Catarina

Câmpus Caçador

\section{SABÃO CASEIRO}

\section{Material Necessário:}

- 80 g de soda cáustica;

- $500 \mathrm{~mL}$ de óleo utilizado em fritura;

- $300 \mathrm{~mL}$ de água;

$$
\text { - Balde plástico; }
$$

- Colher de madeira ou plástico;

- Forma de plástico;

\section{Como fazer:}

- Utilizando o balde adicione a soda cáustica na água; (Nesta ordem, e com auxílio de um adulto);

- Misture bem, em seguida, adicione o óleo;

- Mexer por 20 minutos;

- Transfira para a forma e deixe solidificar.

Ao término das atividades obtiveram-se manifestações efetivas e positivas de vários participantes afirmando que gostaram da atividade e da experiência vivida durante 0 espaço de ensino e de aprendizagem disponibilizado. Alguns deles expressaram suas ideias de como podem contribuir com a separação do óleo usado e com a produção do sabão caseiro para assim diminuir a poluição da água, do solo e evitar o entupimento de tubulações, de forma a contribuir com a redução dos custos referentes ao processo de tratamento da água e de efluentes locais. Alguns professores de disciplinas diversas estiveram presentes nesta atividade, onde destacaram que ficaram contentes com 0 resultado e esperançosos com as transformações que envolvem à conscientização, à cidadania e à autonomia de alunos e da comunidade onde a escola está inserida, que podem ser efetivadas em ações de colaboração do IFSC com as demais escolas.

A avaliação geral da atividade leva a pensar que quanto mais se aplica 0 conhecimento abordado por professores e alunos, sendo depois debatidos e refletidos nos espaços de ensino e de aprendizagem, os mesmos podem sim permitir mudanças substanciais para a constituição de uma sociedade mais interessada com a preservação do meio ambiente, com a valorização das ações coletivas de transformação e com a possibilidade de se interligar as atividades de ensino com práticas e emancipação dos estudantes, agregando um poder transformador na sociedade. Desta maneira, deseja-se reaplicar o projeto futuramente, abordando mais instituições de ensino e disseminando este conhecimento na comunidade regional.

\section{Referências}

ALBERICI, Rosana Maria; PONTES, Flávia Fernanda Ferraz de. Reciclagem de óleo comestível usado através da fabricação de sabão. Engenharia ambiental, v. 1, n. 1, p. 73-76, 2004.

ALLINGER, Norman L.; CAVA, Michael P.; JONGH, Don C. de et al. Química Orgânica. 2. ed. Rio de Janeiro: Ltc, 2009.

LUCENA, Kaiane Pereira; ALBUQUERQUE, Walker Gomes; MOURA, Erika Fernandes. Alternativas ambientais: reciclagem do óleo de cozinha na fabricação de sabão. Informativo Técnico do Semiárido, v. 8, n. 2, p. 08-14, 2014.

PINTO-COELHO, Ricardo Motta; HAVENS, Karl. Gestão de Recursos Hídricos em Tempos de Crise. Porto Alegre: Artmed, 2016. 
SOLOMONS, T. W. Graham; FRYHLE, Craig B.. Química Orgânica. 9. ed. Rio de Janeiro: Ltc, 2011. 2 v.

TOLENTINO, Nathalia Motta de Carvalho. Processos Químicos Industriais: Matériasprimas, técnicas de produção e métodos de controle de corrosão. 1 ed. São Paulo: Érica, 2015. 